\title{
The Impact of COVID-19 on the Health-Related Quality of Life of Individuals Living in Scottish Communities with High Infection Rates
}

\author{
Danielle Campbell ${ }^{1 *}$, Jenny Davison ${ }^{1}$
}

${ }^{1}$ Ulster University, UNITED KINGDOM

*Corresponding Author: dani-c@outlook.com

Citation: Campbell, D. and Davison, J. (2022). The Impact of COVID-19 on the Health-Related Quality of Life of Individuals Living in Scottish Communities with High Infection Rates. European Journal of Environment and Public Health, 6(1), em0099. https://doi.org/10.21601/ejeph/11502

\section{ARTICLE INFO}

Received: 17 Sep. 2021

Accepted: 24 Oct. 2021

\begin{abstract}
A mixed method sequential study explored the impact of COVID-19 by gaining an understanding of how the pandemic has impacted individual experiences as well as examining if these experiences existed across a wider population of residents. Previous research suggests that socio-economic factors have exacerbated the adverse impact of the pandemic, therefore this study sought to explore this, as well as attempt to identify what these implications could mean for COVID recovery.

The study was carried out in two phases. In phase one, semi-structured interviews were undertaken with eight participants, transcribed verbatim and an interpretative phenomenological analysis was conducted. Five themes emerged: self-evaluation and reflection, gratitude, uncertainty, social isolation, and lack of faith in the government were identified. In phase two, standardised measures were administered to assess elicited themes via an online questionnaire. Correlation and multiple regression analyses showed a strong relationship between social isolation, gratitude, uncertainty and HRQoL, with social isolated being a significant predictor.

Despite the limitation of a low variance, evidence of a strong correlation amongst disabled and low-income participants experiencing higher levels of social isolation was found. Uncertainty and levels of gratitude were also found to be correlated with social isolation and HRQoL. Therefore, addressing social isolation should be a priority for mental health services and should influence any future restrictions that may be implemented in a 'third wave' or future pandemic.
\end{abstract}

Keywords: COVID-19, coronavirus, pandemic, HRQoL, social isolation, Scotland

\section{INTRODUCTION}

In December 2019, a novel coronavirus called SARS coronavirus-2 (SARS-CoV-2) was identified in China, the highly contagious, airborne virus quickly spread throughout the world. On the 31st of January 2020 the first case of coronavirus (COVID-19) was confirmed in the United Kingdom (UK), infection rates quickly soared resulting in a UK wide lockdown implemented on the 20th of March 2020. To date (3rd September 2021) there have been over 7.28 million positive cases of the virus in the UK with 152,397 deaths (Yapp and Fordham, 2021).

The COVID-19 pandemic has had a momentous impact on the lives of all UK citizens. Many people's health-related quality of life (HRQoL) from all over the world have been adversely affected because of restrictions such as, social isolation, social distancing, wearing face coverings and not mixing households in addition to the closure of leisure, travel, retail, and hospitality sectors. These measures were imposed to slow the transmission of this deadly virus, but as a result have adversely affected the mental health and economic stability of many individuals (Xiong et al., 2020). In September 2020, eight months after the first UK case of coronavirus, less than two months after lockdown restrictions had eased, a second spike of infection rates resulted in the Scottish Government implementing a five-tier system. Due to the above average numbers of transmissions $\left(\mathrm{R}_{\mathrm{t}}=1.1\right)$, Lanarkshire $\left(R_{t}=1.5\right)$, and Glasgow city council $\left(R_{t}=1.6\right)$ were given the highest level of restrictions resulting in closure of leisure facilities and non-essential stores, as well as a ban on household mixing (Scottish Government, 2021). By December 2020, the entirety of the UK was back in lockdown, with residents in Lanarkshire and Glasgow areas of Scotland living with the highest level of restrictions throughout the full pandemic.

A recent study (Icob et al., 2020) conducted with British adults during the height of the pandemic in May 2020 showed 
a significant increase in reports of suicidal ideation, abuse, self-harm, and mental health issues, particularly from disadvantaged groups. A strong link between mental health issues such as anxiety and depression, and the implementation of restrictions that caused social isolation, loss of routine, and widespread misinformation in the media, has amplified perceptions of risk (Holmes et al., 2020). The risk of a mental health crisis is a priority for the UK government who has introduced helplines and other initiatives in a bid to support the public throughout this pandemic. Alarmingly, national statistics and epidemiology reports have found that COVID-19 and subsequent restrictions have disproportionately affected deprived communities. Mortality and infection rates within low-income areas have also been significantly higher than that of affluent areas, as well as compliance of guidelines wavering in certain areas (Iacobacci, 2020). Unemployment and poverty have soared as a result of restrictions implemented in the UK lockdown as unskilled individuals are less likely to be employed in an industry were working from home is an option and are also more likely to work zero-hour contracts, meaning the closure of retail, manufacturing and hospitality industries resulted in mass redundancies and no income (Patel et al., 2020). The triangulation effect of poverty is an increased risk of homelessness or living in substandard accommodation, as well as poor nutrition which leads to poor overall health and less opportunities for education or employment. This combination often leads to low self-efficacy and a pessimistic outlook that may result in greater risk taking and less adherence to COVID-19 restrictions.

Health-related quality of life (HRQoL) is a subjective construct which evaluates the perceived health of an individual on the sub-dimensions of physical, psychological, social functioning, and wellbeing (Solans et al., 2008). The Scottish Health Survey (2019) conducted annually, shows that HRQoL is generally lower within low-income communities with higher instances of life limiting chronic conditions such as heart disease, diabetes, stroke, and mental health conditions. This suggests that the HRQoL of Lanarkshire and Glasgow residents are most likely to be adversely impacted by the social, emotional, and economic impact of COVID-19. Currently, there are no UK studies investigating the impact COVID-19 has had on HRQoL; however, insightful research is beginning to emerge linking the impact of COVID-19 pandemic on people's HRQoL in other countries.

A quantitative study evaluated the HRQoL of the Chinese population during the COVID-19 pandemic (Ping et al., 2020). The findings show pain and discomfort have raised significantly with ageing, chronic disease, lower income, and epidemic effects. Increased reports of anxiety and depression were linked to feeling worried about contracting COVID-19. Ferreira et al. (2021) quantitative enquiry of QoL during the first two months of Portugal's quarantine revealed similar results. The survey measured QoL and levels of anxiety, finding a positive reciprocal correlation between high anxiety and low QoL. Specifically, levels of anxiety have increased since the beginning of quarantine and were correlated with high scores within the depression dimension of the QoL scale, as a result of the impact of social isolation, growing infection rates and increasing uncertainty experienced by participants (Ferreira et al., 2021). These findings were echoed by Algahtani et al. (2021) who assessed the QoL of Saudi Arabian's during the COVID-19 pandemic and found high instances of social isolation and economic uncertainty were linked to poorer physical, mental, and emotional health of participants. The findings also highlighted that middle-aged men, who had been made unemployed due to the pandemic reported lower QoL across all dimensions as well as higher levels of anxiety and depression.

Given that COVID-19 is an emerging social phenomenon, to date there is a limited body of qualitative research on the impact of COVID-19 on HRQoL within the UK, and for those living in seldom heard communities. As far as the authors are aware, there has not been any qualitative studies investigating personal experiences, particularly of disadvantaged individuals. Exploring the impact COVID-19 has had on individuals from areas with high infection rates will provide valuable insight in to how effective the restrictions and guidelines were in practice which may be advantageous to curb a predicted third wave. As the long-term effects of COVID-19 are not yet known, this study will seek to identify and explore how the pandemic has impacted HRQoL which will provide the foundation of how future policies and interventions can be devised to alleviate the growing mental health crisis in a post COVID-19 society. In gaining a deeper understanding of how this pandemic has impacted individuals, findings will not only help identify what support is needed to improve the quality of life in these areas but also provide knowledge to combat the already entrenched health inequality within the UK.

Both qualitative and quantitative research methodologies were employed. This study adopted a mixed-method sequential design (Sandelowski, 2000) and was conducted in two phases: (1) an elicitation study to explore what impact COVID-19 has had on the HRQoL of individuals living in communities with high infection rates and (2) a quantitative survey to determine if the themes identify in phase one (elicitation study) exist across the wider population, and to gain further insight into the overall impact of COVID-19 on the HRQoL of individuals living in Scottish communities with higher than national average rates of infection.

\section{METHODS}

The aim of this study was to explore the impact of COVID19 on the HRQoL of individuals in Scottish communities with higher than national average rates of infection. An exploratory sequential mixed methods design was conducted in two phases.

\section{Phase 1: Elicitation Study}

\section{Design}

Phase 1 involved a qualitative investigation using semistructured interviews to identify common experiences and psychological impact of COVID-19 on participants. Interviews were conducted using Zoom in December 2020 and lasted between 18-34 minutes ( $\mathrm{M}=23.21$ minutes).

\section{Sample}

Phase 1 strategically recruited a sample of eight individuals aged between 28-66 years ( $M=39.87$ years). Of these, three 
were male and five were female. The majority $(\mathrm{N}=7)$ participants classified themselves as white, with one mixed race. There were a mix of incomes and employment status, 3 were unemployed, 1 a student, 3 in fulltime employment and 1 working part time. Half were living with a chronic health condition or disability, and none had ever received a positive COVID-19 test. All participants were living in the most affected Scottish communities identified by Public Health Scotland (Glasgow city centre, South and North Lanarkshire).

Recruitment was via colleagues and acquaintances within Lanarkshire and Glasgow city centre, (snowball sampling) who then passed on the researcher's details to potential participants within their own network.

\section{Measures}

Questions from the European Quality of Life Survey (EQLS) were adapted from questions for the interview schedule (Eurofound, 2017). These questions elicited personal experiences of the impact of COVID-19 on various domains of the participants HRQoL such as their overall health and wellbeing, social relations, employment, home life and future. In addition to the role government restrictions have had in impacting these domains see Table 1 for full details. Standard demographic questions were then asked at the end of the interview and the participants debriefed.

\section{Procedure}

Once participants got in touch with the researcher to express their interest, participant information sheets were emailed before interview dates and suitable times agreed. The participants were then forwarded a link to join the semi structured interview, which was undertaken on video calling platform, Zoom. Informed consent was verbally obtained, and participants were asked seven open ended questions based on the EQLS (Eurofound, 2017), as well as 10 demographic questions. All interviews were conducted on the video calling platform, Zoom and were audio recorded. The recordings were stored in a password protected hard drive and underwent verbatim transcription, after which the audio files were deleted.

\section{Data analysis}

Once all interviews had been completed and data saturation achieved, all audio recordings were transcribed verbatim and anonymised. An Interpretative Phenomenological Analysis (IPA) (Smith et al., 2009) was conducted with descriptive and linguistic notes being made. Interpretive codes were then devised and clustered together to create sub themes. These identified themes were then grouped together to form a subordinate theme which reflected a common connection shared throughout participant experiences.

\section{Results}

Five superordinate themes were drawn from the analysis and are presented in Table 2 . These are: 1 . Self-evaluation and reflection, 2. Gratitude, 3. Uncertain future, 4. Lack of faith in the government, and 5. Social isolation and sense of confinement.

\section{Self-evaluation and reflection}

On considering the impact of COVID-19 all participants alluded to having time to reflect and evaluate on what is most important to them. Many spoke about feeling like the pandemic provided a much-needed break from their everyday life which allowed them the opportunity to focus on themselves.

"I think if COVID never kicked in I would be because I've had time to reflect and get to know myself a bit more. If, if this happened, [made redundant] and COVID never kicked in, I would have probably had two

Table 1. Interview schedule questions

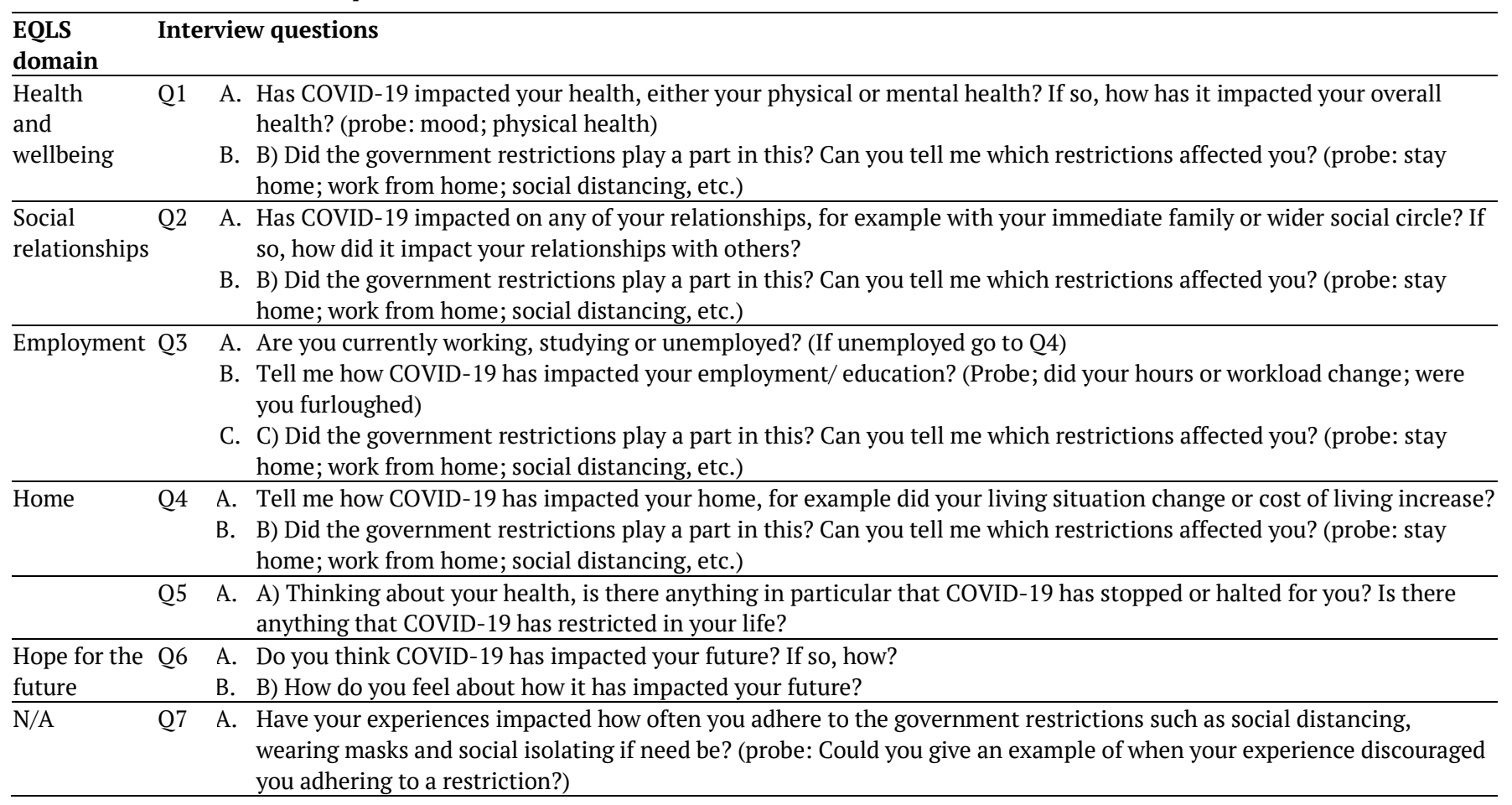


Table 2. Overview of themes

\begin{tabular}{ll}
\hline Superordinate themes & Sub-themes \\
\hline 1. Self-evaluation and reflection & Reflection, questioning values, and life choices \\
\hline 2. Gratitude & Feeling lucky, comparing themselves to others, and appreciating what they have \\
\hline 3. Uncertain future & Fear of unknown and sense of hopelessness \\
\hline 4. Lack of faith in the government & Sceptical of restrictions, finding rules contradictory, and urge to rebel \\
\hline 5. Social Isolation and a sense of confinement & Alone, adapting to stay in contact, a prisoner, and home improvements \\
\hline
\end{tabular}

other jobs at the same time, do you know what I mean? I'd be going off track or stressing out about the fact that I need to find another job and the fact that I've never been like that. So I think that's why. And I know a lot of people are like ah COVID may have helped you a bit and I'm like, well, it kinda did a wee bit I think it's the rest that I needed for next year." (P4)

For some $(n=4$; three that were unemployed and one student) reflected on the impact of the pandemic on their career, which subsequently resulted in them considering a career change and changing their life path as a direct result of COVID-19 experiences.

“Future wise... I don't know where I'm going with that makes sense. Before I knew I was like yeah be an educator, I work in events and I do this, do that. What do I want to do now? And now I'm looking at like, wow, do I even do what I want to do? And I do want to do what I do. But I'm questioning that." (P3)

\section{Gratitude}

All participants mentioned repeatedly that they were grateful to have not contracted COVID-19. In their comparisons to others, participants expressed empathy and gratitude for what they had. For example, feeling in good health, still having a job whilst many others are unemployed, being grateful for having money and a safe house while many others are struggling. Two participants spoke about how they are willing to work extra hours and take on more responsibility because of feeling privileged to be kept on in their job.

"I consider myself very fortunate to be in a job. Frankly, when I see what's happening in the rest of the world, in the private sector, so I consider myself in a very fortunate position, and if I have to work extra hours, and because that's what's required to meet deadlines, and to satisfy external stakeholders, then I'll do that." (P8)

Participant two who has been working in a manual role, expressed how thankful he was to be able to go in to work rather than work from home as it allowed him to maintain the normality of his daily routine and socialising with colleagues.

"Everybody worked from home when they could but unfortunately, I need to be there 'cos I need to build. Erm, so apart from some holidays that I've taken this year, I've been, well I've been in the laboratory full time which, to be honest, I'm actually quite thankful for going in and I've had that as a distraction, I've still been able to see colleagues as well. so yeah, I'd say I am quite thankful for that." (P2)

\section{Uncertain future}

For all participants, in considering the impact of COVID-19 on their future, described feelings of uncertainty, fears of the unknown side effects of the vaccinations, and worries of what the future holds were described.

"It's quite overwhelming when you think about the future because it seems so uncertain right now." (P5)

"I worry what if the vaccine doesn't work? Or what, in 10 or 20 years time, even? That... Oh, my goodness, there's a terrible side effect to the vaccine that we don't know about. So, yeah, there, there is that worry as well.” (P4)

For three participants, a sense of feeling lost and hopeless as a result of the impact of the COVID-19 pandemic were mentioned.

"I sometimes feel a bit hopeless. Sometimes, like you sit and you think... well, what's the point? Sometimes when you get up the morning, you don't even have to know what day it is. It's all about Groundhog Day. so...Yeah, I would say sometimes you're not sure what. And it's scary, scary not knowing what the future will be, that is scary." (P7)

One unemployed participant, reflected on how her employment prospects have changed due to the pandemic which has caused a lot of uncertainty of her future and the impact it will have on the family's finances.

"My future's pretty uncertain at the moment. Obviously, my, erm, in what I want to do work wise... That, I think is changing. So, I feel my future's really uncertain at the moment. And what I'm going to be doing workwise, when or if, I'll be able to get a job, how we're going to manage financially. And yeah, it's, it's very up in the air." (P1)

\section{Lack of faith in the government}

For all participants' scepticism of the restrictions, feeling that the rules were contradictory, and trusting their own judgement over the government guidelines were highlighted.

"In my husband's business he always wore PPE cos he is a cosmetic tattooist, so He always wore a mask, he always wore a visor. Everything was always wiped clean. He's not allowed to work. But you can go to a classroom and sit with 35 other people, I can't get my head around that so sometimes I was feeling that way of going shove it! Your rules that a lot of nonsense." (P6) 
Several participants also said they used nonadherence as a sort of rebellion to the government.

"I would just be like, Ah, you know what, bugger it, I'm just gonna do it anyway. They can't stop me from living my life. That was... That was definitely my mantra for a while until I kinda realised that it wasn't the right thing to do." (P2)

\section{Social isolation and a sense of confinement}

All participants suffered from social isolation as a result of the COVID-19 pandemic. Feelings of being "stuck at home" and feeling isolated from friends and family were experienced. The majority of participants expressed the sense of feeling trapped and not able to go out or be free.

"I definitely see myself now just kind of sitting alone in the living room... feeling a bit of a prisoner in my own home at times.” (P2)

Positive experiences of the COVID-19 pandemic were also discussed by two participants, who reflected on having used the time for making home improvements, whether internal decorating or outside garden renovations. Others mentioned being able to save money to buy materialistic goods for their home, e.g., a new TV.

"I got my garden done up because we were spending more time in the garden so I got fake grass. We repainted the living room because we were in more. We got a new TV because we'd saved up for the special birthday and I was like what are we going to do... nothing? Well spend that money on a new TV because we seem to be watching more telly.” (P6)

For one participant, the experience of self-confinement resulted in realisation of her living standards, e.g., realising how dilapidated her house is, but as a result of the pandemic was unable to move due to the restrictions.

“There was a lot of issues that I noticed that I wouldn't have. I mean, I don't know I've been battling with the landlord for a while to be honest. But it's not until lockdown that it's actually impacted our health because we've been at home consistently. And I would say that it's been hard because I'm... I feel a bit isolated. If you know what I mean. I had like, there's dampness in more or less in all the rooms and it's been diagnosed raising and penetrating dampness... so it's like my bedroom and my boys' room was the only room that doesn't have dampness in it, which was a bit of a saving grace to be honest, because that was like a safe place. So when I found I think it was about seven weeks ago or something I found some dampness in my room, I just broke down. I was like, that was me, I was like that's my safe place gone now, like that's it!” (P4)

Within this superordinate theme a further sub-theme was identified: Adapting to stay connected.

As a result of restrictions on face-to-face contact, all participants spoke about adapting their communication processes to stay in touch with friends and family through the use of online platforms, i.e. zoom calls and instant messages, and writing letters/posting cards. This was viewed as both a positive as well as negative consequence of not being able to physically visit in person.

“I miss lots of my friends, and I thought it'd be a nice gesture to try and keep in touch with them. So we were doing the zoom parties and zoom quizzes and things like that. We were sending each other gifts and cards which was really nice. That you don't usually do and don't usually, as much as they are my friends and I see them often. I can't remember the last time I just sent them random gifts and cards, or they did the same to me so that was nice at the beginning it felt really nice and really warm" (P6)

Many participants also spoke about adapting the rules to ensure they still interacted with loved ones, such as forming an extended bubble and tailoring guidelines to provide justification for their actions. The common reasons for this were either to allow participants to support their family members or to preserve their own mental health.

“I have been going into my mum's and I need to because if I never got that trip done in my mum's I will have cracked up being on my own all the time. Because my partner and daughter are at school and work all day. I'm in the house all day on my own. If I am in the house all day on my own seven days a week without interacting with family members, I don't think I would be able to cope. And I know I'm not supposed to but I still go to my mum's house, And I need to.” (P3)

\begin{abstract}
"I knew how much it had impacted me not being able to see my friends and family and stuff but my daughter is finding it really hard and she's filled with anxiety. So kind of took advantage of the whole if you're with, if you have a partner you can see them non cohabiting couple type thing and I'll let her have our best friend in our house because I said if she was your girlfriend she would be allowed in the house so she's your best friend you are with her outside all the time, it is freezing cold so you can have her in our house and basically she was in our house but she used the downstairs toilet and didn't move beyond the living room." (P5)
\end{abstract}

\section{Phase 2: Quantitative Study}

\section{Design}

In phase 2 an online quantitative survey hosted by Qualtrics was utilised to determine if the emergent themes elicited in phase one of the study existed across the wider population, as well as assessing the overall impact of COVID19 on the HRQoL of individuals living in Scottish communities with higher than national average rates of infection.

\section{Sample}

A total of 267 participants completed the questionnaire with a mean age of 34.8 years. Of these, the majority were female $(92 \% ; \mathrm{N}=245)$ and white $(98 \% ; \mathrm{N}=261)$. The majority of participants $(93 \% ; \mathrm{N}=240$ ) had not tested positive for COVID19 , reported being in good health $(45 \% ; \mathrm{N}=122)$ and did not 
have a chronic condition or disability ( $74 \% ; \mathrm{N}=197)$. There was an even mix of household incomes ranging from under $£ 16 \mathrm{k}$ $(14 \% ; \mathrm{N}=35)$ to over $£ 60 \mathrm{k}(27 \% \mathrm{~N}=67)$.

\section{Measures}

An online questionnaire was hosted by Qualtrics XM Software and contained 80 questions, of which 10 of these were social demographic questions, e.g. (gender, age, etc.). Informed consent (tick-box) was obtained at the start of the survey after participants read the information sheet.

The questionnaire comprised of five scales measuring the identified themes from the phase 1 qualitative study. The five scales are as follows:

(1) Perceived isolation scale (Cornwell and Waite, 2009): This scale comprises of two sections. Section one includes 8 items measuring social disconnectedness using Likert scales that determine the size and frequency of interactions with a respondent's social networks. Section two includes 9 items that measure perceived isolation over the past 12 months, measured using a three-point Likert scale ranging from hardly ever/never (1) to often (5). Sample items include: How often do you feel that you lack companionship? These items determine frequency of support from friends and family.

(2) The gratitude, resentment, and appreciation test (GRAT) (Watkins, 2003): The gratitude, resentment, and appreciation test (GRAT) contain 16 items to measure feelings of gratitude or resentment. Items are assessed across a 5-point Likert scale ranging from strongly agree (1) to strongly disagree (5) to determine how strongly the respondents agree or disagree with each of the statements.

(3) The self-reflection and insight scale (Grant et al., 2012): This 16-item scale measures the respondent's engagement in self- reflection and their insight into their own thoughts and behaviour. Each statement is answered by a 5 point strongly agree/disagree scale.

(4) The intolerance of uncertainty (IUS-12) (Carleton, et al., 2007): This scale is a shortened version of the 27-item Intolerance of Uncertainty Scale (IUS) which was developed to measure intolerance of uncertainty. The short version includes 12 items measuring respondents' feelings of uncertainty and how they would cope in various uncertain situations. Each item is assessed using a 5-point Likert scale ranging from "Not at all characteristic of me" (1) to "Entirely characteristic of me" (5).

COVID-SCORE-10 scale (Lazurus et al., 2020): This scale measures participants trust in government and the response to the COVID-19 pandemic. The scale consists of 10 items measured on a 5-point Likert scale ranging from strongly agree to strongly disagree.

\section{Procedure}

Following the interviews, Phase 2 involved disseminating an online questionnaire to participants over the age of 18 living within the targeted areas of Glasgow city centre, South and North Lanarkshire. A link to the questionnaire was emailed to partners and services within these areas and encouraged to disseminate to service users to invite to participate in the study, an anonymous link and description of the study was also shared to local community groups on social media. Participants then chose to participate by clicking the link, reading the participant information sheet, and providing consent to participate. Data collection was open from the 22nd of February 2021 to 8th March 2021 where a total of 267 participants completed the online questionnaire on Qualtrics XM Software.

\section{Data analysis}

Data was exported from Qualtrics to SPSS (version 26), cleaned and prepared for statistical analysis. A descriptive and correlational analysis were conducted to explore the association between scales. A multiple regression analysis was then undertaken to explore the extent of these associations and determine if these correlations were statistically significant.

\section{Ethical approval and consent}

Prior to data collection, ethical permission was sought and granted from the School of Psychology Staff and Postgraduate Filter Committee, Ulster University. The British Psychological Society's ethical guidelines was closely adhered to throughout the entire research procedure (British Psychological Society, 2014). Steps were taken to address any potential ethical concerns and standard consent procedures were followed.

Results

\section{Psychometric properties}

Prior to statistical analysis, internal consistency tests were computed on each of the scales of measurement using Cronbach's alpha reliability co-efficient (Cronbach, 1951). Table 3 shows such values.

Table 3. Cronbach's alpha reliability co-efficient

\begin{tabular}{cc}
\hline Scale & Alpha \\
\hline SI & .71 \\
\hline$G R$ & .83 \\
\hline$U c$ & .90 \\
\hline$T G$ & .91 \\
\hline$S R$ & .61 \\
\hline
\end{tabular}

\section{Descriptive statistics}

Table 4 shows the descriptive statistics of our study.

Table 4. Descriptive statistics

\begin{tabular}{cccccc}
\hline Variable & Range & Max. & Min. & Mean & SD \\
\hline HRQoL & 4 & 1 & 5 & 2.56 & 1.21 \\
\hline SI & 34.00 & 14.00 & 48.00 & 30.65 & 6.11 \\
\hline GR & 44.00 & 18.00 & 62.00 & 32.99 & 8.05 \\
\hline UC & 44.00 & 13.00 & 57.00 & 30.47 & 9.83 \\
\hline TG & 39.00 & 11.00 & 50.00 & 28.06 & 9.50 \\
\hline SR & 39.00 & 32.00 & 71.00 & 50.86 & 5.19 \\
\hline
\end{tabular}

\section{Prediction of HRQoL}

Pearson correlation coefficients were computed to investigate the relationship between HRQoL and the predictor variables contained within the questionnaire, namely social isolation, gratitude, uncertainty, trust in the government and 
self-reflection. As illustrated in Table 5, three of the predictor variables were significantly correlated with HRQoL $(p<.01)$. The strongest relationship was with social isolation, followed in descending order, by gratitude/ resentment, and uncertainly. Neither trust in government or self-reflection accounting for predicting HRQoL amongst the target group.

Table 5. Correlations between HRQoL and variables

\begin{tabular}{ccccccc}
\hline Variable & HRQoL & SI & GR & UC & TG & SR \\
\hline HRQoL & - & & & & & \\
\hline SI & $.337^{* * *}$ & - & & & & \\
\hline GR & $.296^{* *}$ & $.467^{* * *}$ & - & & & \\
\hline UC & $.235^{* * *}$ & $.273^{* *}$ & $.337^{* * *}$ & - & & \\
\hline TG & .061 & $.158^{*}$ & $.220^{* *}$ & .041 & - & \\
\hline SR & .083 & -.040 & .015 & $.182^{*}$ & $-.152^{* *}$ & - \\
\hline
\end{tabular}

***Correlation is significant at the 0.01 level/*Correlation is significant at the 0.05 level

These relationships between HRQoL and the predictor variables were further explored through a regression analysis, the results of which are displayed Table 6. As illustrated in the Table 6 , only $12.8 \%$ of the variance $\left[R^{2}(5,197)=5.804\right.$, p $p<.001]$ in HRQoL was explained by social isolation, gratitude, uncertainty, trust in the government and self-reflection. Only social isolation proved a significant predictor $(\beta=-.273$, $p<.001)$.

Table 6. Regression analysis

\begin{tabular}{|c|c|c|c|}
\hline HRQoL & $\mathbf{R}$ & $\mathbf{R}^{2}$ & Beta \\
\hline SI & \multirow{5}{*}{.358} & \multirow{5}{*}{.128} & $-.273^{* * *}$ \\
\hline GR & & & -.102 \\
\hline $\mathrm{UC}$ & & & -.068 \\
\hline TG & & & .077 \\
\hline SR & & & -.067 \\
\hline
\end{tabular}

***Correlation is significant at the 0.01 level/*Correlation is significant at the 0.05 level

Further analysis was undertaken to examine if sociodemographic factors such as age, gender, employment status, income and living with a disability were correlated with HRQoL and Social Isolation. Table 7 shows there are a strong relationship between HRQoL and Income, disability and living arrangement as well as social isolation and Disability and living arrangement. Gender and age did not show any such correlations.

Table 7. Correlations between HRQoL, SI and sociodemographic factors

\begin{tabular}{|c|c|c|c|c|c|}
\hline Variable & HRQoL & SI & Income & Disability & $\begin{array}{c}\text { Living } \\
\text { arrangement }\end{array}$ \\
\hline HRQoL & - & & & & \\
\hline SI & $.331 * *$ & - & & & \\
\hline Income & $.313 * *$ & -.097 & - & & \\
\hline Disability & $.403 * *$ & $.233 * *$ & $-.261 * *$ & - & \\
\hline $\begin{array}{c}\text { Living } \\
\text { Irrangement }\end{array}$ & $.180^{* * *}$ & $.185^{* * *}$ & $.408 * *$ & $.298 * *$ & - \\
\hline
\end{tabular}

*** Correlation is significant at the 0.01 level $/ *$ Correlation is significant at the 0.05 level

\section{DISCUSSION}

This analysis sought to identify if the COVID-19 pandemic, subsequent lockdowns, and regular restrictions had a significant impact on the health-related quality of life (HRQoL) of individuals living in Scottish communities with higher than national average rates of infection. Findings suggest that factors such as social isolation, uncertainty, and feelings of gratitude were most impactful in both phases of the study. Subsequent themes of lack of trust in the government, increased self-reflection, and insight were also uncovered through IPA analysis during phase one, however, these themes were not found to be significant during quantitative investigation in phase 2 . This difference in findings between phases may be due to the context of the questions asked during the semi-structured interviews or, perhaps because the task of answering the questions encouraged participant's reflection and insight.

Social isolation was most strongly associated with HRQoL. This is evidenced throughout both phases as it was a common theme throughout all interviews and high levels of social isolation correlated with low HRQoL. The positive effect of social support is widely recognised, as is the adverse impact of loneliness and social isolation throughout the pandemic which has been linked to increased rates of depression, anxiety, and pessimism in recent studies (Algahtani et al., 2021; Ferreira et al., 2021). This study's findings highlight the detrimental impact that restrictions which limit social interactions have had on HRQoL, as the data also shows that an increase in social isolation is correlated to feelings of resentment and uncertainty which are the foundations of poor mental health and low mood. This supports Algahtani et al.'s (2021) findings that detail numerous negative effects of social isolation during lockdowns in Saudi Arabia and discussed the impact of uncertainty on participant's mental health.

The impact of the pandemic on those experiencing disability was explored. Experiencing disability correlated with lower HRQoL, as well as being associated with social isolation. This supports findings by Ping et al. (2020) which also found that the quality of life of individuals with chronic conditions are more likely to be lower because of increased social isolation. This could be a result of shielding where vulnerable members of society had to remain exclusively at home without any social interactions or because individuals living with chronic conditions, or a disability may have increased barriers to adapted contact such as online video calling or going for walks.

Limited resources may be a contributing factor in low HRQoL throughout the pandemic. The data also shows sociodemographic factors such as a low income or living alone were strongly correlated to low HRQoL which supports previous studies (Iacobacci, 2020; Lob et al., 2020; Patel et al., 2020). The detrimental impact on lower socio-economic status, unemployment, and poorer living standards were recurring throughout the qualitative phase with unemployed and lowincome participants reporting more feelings of isolation, poorer health, financial stress, future uncertainty, and unsuitable housing. However, a theme that emerged was feelings of gratitude for what the participants had and that 
things were not worse. Many participants compared their situation to others and expressed gratefulness for their health, specifically not having contracted COVID-19 whilst many others had lost their lives because of it. This was an interesting insight as it contested Holmes et al. (2020) findings that highlighted the negative impact exposure to the intense media coverage, daily updates of hospitalisation and death rates that were shown throughout the pandemic may have had on the public. These were not discussed amongst participants in this study; however, Bono et al. (2020) suggest that this coverage could have contributed to the viewer's feelings of gratitude as it has allowed the public to see the tragic consequence of the pandemic from the safety of their homes. Bono et al. (2020) also found that gratitude may act as a protective factor because the individual could draw comparisons which made them feel lucky and grateful for their own situation, even if they lacked material resources their health is seen as a blessing. Solans et al. (2008) highlights the benefits of social functioning which supports the suggestion that employment may also have acted as a protective factor with participants expressing relief at still having employment, even though their role and hours of work may have become more challenging because of the pandemic. This may be due to the psychological benefits of employment such as a sense of purpose and achievement as well as the positive impact social functioning has on HRQoL, particularly at a time where you are confined to your own home most of the time due to lockdowns or the restrictions.

The data from phase 2 echoes these feelings of gratitude finding a positive correlation between high levels of gratitude and a high HRQoL, as well as a strong correlation between high levels of gratitude and low social isolation. This suggests that during the pandemic individuals may have valued their social relationship and felt grateful for the support networks they have within their lives. However, unlike social isolation, gratitude was not found to be a significant predictor of HRQoL, this may be due to the low variance of the sample which is a limitation of this study.

Whilst the samples in both phases featured an even mix of household incomes, participants on lower incomes and those unemployed expressed a great deal more uncertainty and concern about the future. This disproportionate impact of the pandemic on individuals in low socio-economic supports Iacobacci (2020) as the participant's showing the highest level of uncertainty for the future were often unskilled and had previously worked in industries impacted by the pandemic, i.e hospitality and events, this led to feelings of hopelessness and worry of what they will do for employment. This theme of uncertainty was explored further during phase 2 and a positive relationship was found between low levels of uncertainty and high levels of gratitude, this also suggests that employment security and feeling thankful for good health may reduce apprehension of the future. These findings support the triangulation effect of poverty, health and social isolation detailed in Patel et al. (2020) study as well as highlight the impact COVID-19 has had on widening health inequalities as the most acutely impacted residents are those who are disabled, unemployed, and on a low income.

This study has addressed a gap in this research area and provides much-needed qualitative research that explores individual's experiences and provides increased context to how the pandemic has impacted their HRQoL. The findings provide strong guidance on priority areas for post COVID recovery and highlight the need for future mental health interventions to address social isolation, integrate social opportunities that combat loneliness and encourage.

This study has provided insight into the emerging knowledge of the impact COVID-19 has had not only within Scotland but on seldom heard groups. However, a significant limitation of this study is the homogeneity with the majority of participant's being white and female, particularly within the second phase. Whilst the lack of BAME participants may be reflective of the Scottish population (96.02\% estimated to be white) it may also limit the findings as previous studies have shown that BAME communities were more adversely impacted by COVID-19. Further studies should be conducted exploring the relationship between ethnicity, low socio-economic status and low HRQoL as a result of the COVID-19 pandemic. This will also help provide data to assess the extent the pandemic has widened health inequalities.

This study has explored how two lockdowns and ongoing restrictions throughout the COVID-19 pandemic (from March 2020 to July 2021) has impacted the HRQoL of residents from Scottish communities with high infection rates. The mixed method approach employed has provided robust evidence that social isolation has had the most detrimental impact on HRQoL with a strong correlation amongst disabled and lowincome residents experiencing higher levels of social isolation. Uncertainty and levels of gratitude were also found to be correlated with HRQoL although, this was not found to be a significant predictor.

These findings should be considered by policy makers in the event of any future restrictions implemented in a 'third wave' or future pandemic. Steps should be taken to minimise the adverse impact of social isolation and its knock-on effect to gratitude and uncertainty, which may safeguard the HRQoL of residents. Mental health interventions to support the longterm effects of the pandemic should also consider these findings and seek to implement opportunities for social interactions and positive psychology practices that encourage gratitude.

Funding: No external funding is received for this article.

Declaration of interest: The author declares that no competing interests.

Ethics approval and consent to participate: Not applicable.

Availability of data and materials: All data generated or analyzed during this study are available for sharing when appropriate request is directed to corresponding author.

\section{REFERENCES}

Algahtani, F. D., Hassan, S. U. N., Alsaif, B. and Zrieq, R. (2021). Assessment of the quality of life during COVID-19 pandemic: A cross-sectional survey from the kingdom of Saudi Arabia. International Journal of Environmental Research and Public Health, 18(3), 847. https://doi.org/ 10.3390/ijerph18030847 
Bono, G., Reil, K. and Hescox, J. (2020). Stress and wellbeing in urban college students in the US during the COVID-19 pandemic: Can grit and gratitude help? International Journal of Wellbeing, 10(3), 39-57. https://doi.org/10.5502/ ijw.v10i3.1331

Bottesi, G., Ghisi, M., Novara, C., Bertocchi, J. et al. (2015). Intolerance of uncertainty scale (IUS-27 and IUS-12): Two preliminary studies. Psicoterapia Cognitiva $e$ Comportamentale, 21(3), 345-365.

British Psychological Society. (2014). BPS code of human research ethics (2nd ed.). Available at: https://www.bps.org. uk/news-and-policy/bps-code-human-research-ethics2nd-edition-2014

Cornwell, E. Y. and Waite, L. J. (2009) Social disconnectedness, perceived isolation, and health among older adults. Journal of Health and Social Behavior, 50(1), 31-48. https://doi.org/ 10.1177/002214650905000103

Diessner, R. and Lewis, G. (2007). Further validation of the gratitude, resentment, and appreciation test (GRAT). The Journal of Social Psychology, 147(4), 445-447. https://doi.org/10.3200/SOCP.147.4.445-448

Eurofound. (2017). European quality of life survey 2016. Available at: https:/www.eurofound.europa.eu/sites/defa ult/files/ef_publication/field_ef_document/ef1733en.pdf

Ferreira, L. N., Pereira, L. N., da Fé Brás, M. and Ilchuk, K. (2021). Quality of life under the COVID-19 quarantine. Quality of Life Research, 30(5), 1389-1405. https://doi.org/10.1007/s11136-020-02724-X

Gao, J., Zheng, P., Jia, Y., Chen, H. et al. (2020). Mental health problems and social media exposure during COVID-19 outbreak. PLoS One, 15(4), e0231924. https://doi.org/ 10.1371/journal.pone.0231924

Grant, A., Franklin, J. and Langford, P. (2002). The selfreflection and insight scale: A new measure of private selfconsciousness. Social Behavior and Personality: An International Journal, 30, 821-835. https://doi.org/10.2224/ sbp.2002.30.8.821

Holmes, E. A., O’Connor, R. C., Perry, V. H., Tracey, I. et al. (2020). Multidisciplinary research priorities for the COVID19 pandemic: A call for action formental health science. Lancet Psychiat, 7, 547-560. https://doi.org/10.1016/S22150366(20)30168-1

Iacobacci, G. (2020). COVID-19: Deprived areas have the highest death rates in England and Wales. BMJ, 2020, 369. https://doi.org/10.1136/bmj.m1810

Iob, E., Steptoe, A. and \& Fancourt, D. (2020). Abuse, selfharm and suicidal ideation in the UK during the COVID-19 pandemic. The British Journal of Psychiatry, 217(4), 543-546. https://doi.org/10.1192/bjp.2020.130
Lazarus, J. V., Ratzan, S., Palayew, A., Billari, F. C. et al. (2020). COVID-SCORE: A global survey to assess public perceptions of government responses to COVID-19 (COVID-SCORE-10). PLoS One, 15(10), e0240011. https://doi.org/10.1371/ journal.pone.0240011

Patel, J. A., Nielsen, F., Badiani, A. A., Assi, S. et al. (2020). Poverty, inequality and COVID-19: The forgotten vulnerable. Public Health, 183, 110-111. https://doi.org/ 10.1016/j.puhe.2020.05.006

Ping, W., Zheng, J., Niu, X., Guo, C. et al. (2020). Evaluation of health-related quality of life using EQ-5D in China during the COVID-19 pandemic. PLoS One, 15(6), e0234850. https://doi.org/10.1371/journal.pone.0234850

Sandelowski, M. (2000). Combining qualitative and quantitative sampling, data collection and analysis techniques in mixed-method studies. Research in Nurse \& Health, 23(3), 246-255. https://doi.org/10.1002/1098240X(200006)23:3<246::AID-NUR9>3.0.CO;2-H

Scottish Government. (2021). Coronavirus (COVID-19): Modelling the epidemic (Issue no. 19). Available at: https://www.gov.scot/publications/coronavirus-COVID19-modelling-epidemic-issue-no-19/

Smith, J. A. and Osborn, M. (2012). Interpretative phenomenological analysis. In H. Cooper, P. M. Camic, D. L. Long, A. T. Panter et al. (Eds.), APA handbook of research methods in psychology (Vol. 2., pp. 73-82). American Psychological Association. https://doi.org/10.1037/13620005

The Scottish Health Survey. (2019). Scottish Government Health Directorates. Available at: https://www.gov.scot/ collections/scottish-health-survey/

Watkins, P. C., Woodward, K., Stone, T. and Kolts, R. L. (2003). Gratitude and happiness: Development of a measure of gratitude, and relationships with subjective well-being. Social Behavior and Personality, 31(5), 431-451. https://doi.org/10.2224/sbp.2003.31.5.431

Xiong, J., Lipsitz, O., Nasri, F., Lui, L. M. W. et al. (2020). Impact of COVID-19 pandemic on mental health in the general population: A systematic review. The Journal of Affective Disorders, 277, 55-64. https://doi.org/10.1016/ j.jad.2020.08.001

Yapp, R. and Forham, E. (2021). Coronavirus (COVID-19) infection survey, UK: 3 September 2021. Available at: https://www.ons.gov.uk/peoplepopulationandcommunity/ healthandsocialcare/conditionsanddiseases/bulletins/coro navirusCOVID19infectionsurveypilot/3september2021 